\title{
Grapphia: Aplicativo para Dispositivos Móveis para Auxiliar o Ensino da Ortografia
}

\author{
Luciana Assis $^{1}$, Adriana Bodolay ${ }^{1}$, Luiz Otávio M. Gregório ${ }^{1}$, \\ Magno Juliano G. Santos ${ }^{1}$, Alessandro Vivas ${ }^{1}$, Cristiano Pitangui ${ }^{1}$, Daniela Perry ${ }^{1}$ \\ ${ }^{1}$ Universidade Federal dos Vales do Jequitinhonha e Mucuri (UFVJM) \\ Diamantina - MG - Brazil \\ \{lpassis, adriana.bodolay, luiz.otavio\}@ufvjm.edu.br \\ \{magno.santos, alessandro.vivas\}@ufvjm.edu.br \\ \{pitangui.cristiano, perribandeira.daniela\}@gmail.com
}

\begin{abstract}
The present work aims to auxiliary to the teaching of the Portuguese language, especially spelling, from the use of a digital application for mobile devices. This application is designed to serve an group of children between 8 to 10 years of age. The methodology consists in the creation of a database of words from the same semantic field that are frequent in the children's vocabulary, which responds to the question of more than one graphic representation for the same sound. Based on these data, a mobile application was proposed, addressing this spelling difficulties.
\end{abstract}

Resumo. O presente trabalho tem por objetivo auxiliar o ensino da língua portuguesa, em especial da ortografia, a partir do uso de um aplicativo digital para dispositivos móveis. Este aplicativo foi projetado para atender a uma faixa etária de crianças entre 8 a 10 anos. A metodologia consiste na criação de uma base de dados de palavras de um mesmo campo semântico frequentes no vocabulário de crianças, que atenda ao quesito de mais de uma representação gráfica para um mesmo som. Com base nesses dados, foi proposto um aplicativo para dispositivos móveis, abordando estas dificuldades ortográficas.

\section{Introdução}

O processo de aprendizagem de uma língua no ambiente formal passa pelo desenvolvimento de habilidades orais e escritas. É papel da escola proporcionar meios para que os alunos possam entrar em contato com a variante padrão, reconhecendo-a e utilizando-a de forma proficiente. Trata-se de um dos objetivos centrais parametrizado pelos Parâmetros Curriculares Nacionais [Brasil 1997] para o ensino da área de Língua Portuguesa (LP).

Antes mesmo de se organizar o ensino das capacidades de LP nos currículos escolares, a preocupação com a aprendizagem da ortografia perpassa a discussão sobre as fases do processo de alfabetização, isto é, a aquisição das capacidades de ler e escrever. Dentre os conteúdos elencados para o ensino de LP, encontra-se a ortografia.

Vale ressaltar o caráter convencional da norma ortográfica, na qual se identificam duas grandes categorias. A primeira delas é aquela que se verifica a existência de palavras grafadas controladas por uma regra, em que a sua forma de dicionário possui uma 
VI Congresso Brasileiro de Informática na Educação (CBIE 2017)

Anais dos Workshops do VI Congresso Brasileiro de Informática na Educação (WCBIE 2017)

motivação para a escrita, como é o caso de palavras derivadas (casinha é escrita com $s$ porque vem do substantivo primitivo casa). De forma diferente, a segunda categoria, as palavras irregulares, não é controlada por uma regra: nesse caso, há letras concorrentes, não sendo possível identificar uma razão sistemática para a escolha de uma ou outra letra, como ocorre em casa (que poderia ser grafada com $z$, se essa fosse a convenção). Nos dois casos, é necessário um trabalho sistematizado do professor, seja para construir as regras ou para exercitar a memória do aluno para o aprendizado do segundo grupo [Alvarenga 1995].

Assim sendo, a proposta do presente trabalho é articular as reflexões do campo do ensino da ortografia com a possibilidade de desenvolvimento tecnológico para dispositivos móveis. Dessa forma, objetiva-se o desenvolvimento de um aplicativo digital, direcionado a crianças já alfabetizadas e que possam, portanto, apresentar dúvidas quanto ao nível ortográfico, a partir da problematização de um conteúdo de ensino da Língua Portuguesa na educação básica.

O problema da nossa pesquisa é, no contexto atual do ensino de LP, qual seria a melhor metodologia para se ensinar as dificuldades ortográficas que não são motivadas por regras? A nossa hipótese se baseia na ideia de [Alvarenga 1995], para quem a aprendizagem desse grupo de palavras irregulares depende do uso da memória e que, portanto, cada palavra deve ser aprendida individualmente. Dessa forma, para o exercício de memorização, o uso de jogos torna-se a forma mais apropriada para que a criança consiga grafar as palavras de acordo com a convenção do dicionário.

[Gaspar et al. 2015] apresentam um Mapeamento Sistemático da Literatura (MSL), demostrando uma visão geral de trabalhos envolvendo ensino da Língua Portuguesa com uso de dispositivos móveis. $\mathrm{O}$ autor mostra que existem ainda poucos trabalhos relacionados na área entre os anos 2009 a 2014. Em geral, os trabalhos abordam temas específicos da Língua Portuguesa. Dentre os trabalhos encontrados, acentuação e hífen são os conteúdos mais abordados devido ao novo acordo Ortográfico de 2009.

Para delimitar o campo ortográfico a ser abordado no aplicativo proposto, foram analisadas diferentes dificuldades ortográficas e quais seriam adequadas de serem tratadas no contexto do m-learning. Conforme classificação apresentada por [Zorzi 2003], existem diferentes erros ortográficos. O autor constatou que os erros por representação múltipla apresentavam maior incidência.

Segundo [Morais 2005], a escrita de palavras irregulares, como é o caso das palavras "reza" e "mesa", foram determinadas levando em conta as suas questões históricas. Os hábitos de uso dessas palavras no passado fizeram com que suas formas de escrita se tornassem convencionais.

Assim, para que a criança aprenda a maneira correta de se escrever esse conjunto de palavras, é necessário recorrer ao dicionário, tendo que decorá-las. Porém, memorizar essas palavras uma a uma pode ser um processo bastante desgastante. Para minimizar esse possível problema, métodos alternativos de ensino podem ser explorados fazendo com que essa aprendizagem se torne mais interessante e intuitiva. Existem diferentes propostas de aplicativos para auxiliar o ensino da Língua Portuguesa [Paschoal et al. 2014, Araújo et al. 2016, Ouverney-King et al. 2016], porém, conforme constatado no trabalho de [Gaspar et al. 2015], nenhum dos trabalhos relacionados apre- 
VI Congresso Brasileiro de Informática na Educação (CBIE 2017)

Anais dos Workshops do VI Congresso Brasileiro de Informática na Educação (WCBIE 2017)

sentaram aplicativos para essa finalidade. Conclui-se, então, que se trata de uma lacuna importante e necessária de se explorar.

\section{Grapphia: Aplicativo para Auxiliar o Ensino da Ortografia}

O aplicativo Grapphia foi proposto para auxiliar o ensino da grafia de palavras que possuem letras ou dígrafos concorrentes, que representam o mesmo som. Para desenvolvimento do aplicativo foi utilizado a ferramenta Unity [Unity 2017]. O público alvo são crianças entre 8 e 10 anos. A tarefa a ser executada pelo usuário é completar palavras apresentadas na tela selecionando uma letra entre duas opções de resposta.

A partir da tela inicial, apresentada na figura 1, o usuário passa pela fase de identificação no sistema, em que existem as opções de cadastrar um novo usuário ou selecionar um usuário já existente. A figura 1 também retrata as telas de cadastro e seleção de usuário.
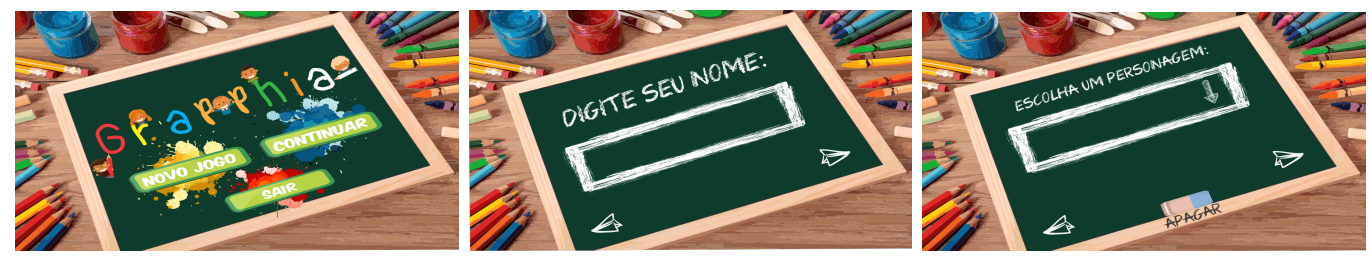

Figura 1. Tela inicial e de identificação do usuário

Uma vez definido o usuário, o sistema apresenta uma prateleira na qual estarão contidos os diferentes módulos que o compõem, representados por diferentes livros. Inicialmente, a primeira versão do sistema conta apenas com o livro "A Fazenda" que apresenta um conjunto de palavras grafadas com "s" ou "z" concorrentes. O título escolhido para o livro já retrata um exemplo dessa dificuldade ortográfica. A figura 2 representa a parte de seleção de módulo do sistema.

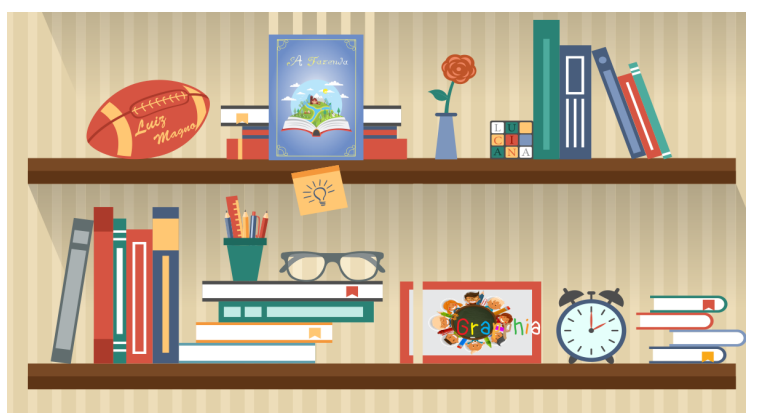

Figura 2. Tela de seleção de módulo. O livro "A Fazenda"é o primeiro módulo disponível na primeira versão do sistema.

Uma vez selecionado um livro, o aplicativo apresenta um conto criado especificamente para o jogo. O livro "A Fazenda" retrata a história de duas crianças que estão passeando em uma fazenda. Várias palavras grafadas com "s" e " $z$ " concorrentes são utilizadas no conto: paisagem, buzina, azul, tesoura, casamento, rosas, raposa, dentre outras. A criança também tem à disposição um botão de áudio no qual ela pode ouvir o mesmo texto escrito. O principal objetivo da história é proporcionar um primeiro contato das 
VI Congresso Brasileiro de Informática na Educação (CBIE 2017)

Anais dos Workshops do VI Congresso Brasileiro de Informática na Educação (WCBIE 2017)

crianças com as palavras dentro de um contexto. Além disso, não seria eficiente trabalhar palavras irregulares sem que a criança tenha conhecimento da forma ortográfica. A figura 3 apresenta a capa do livro e uma parte da história.

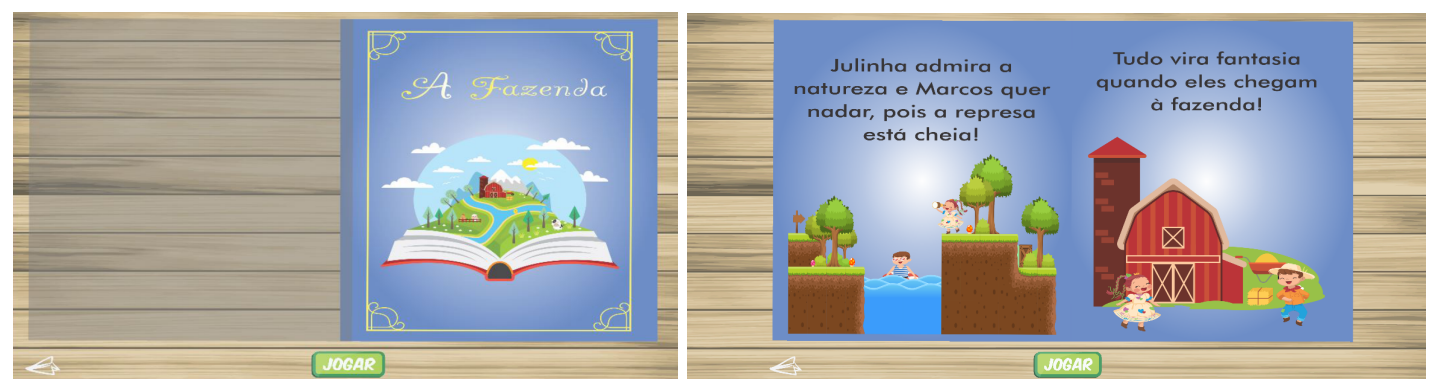

Figura 3. Telas do livro que contém história, contextualizando as palavras irregulares que serão trabalhadas no módulo selecionado.

Ao terminar a leitura o usuário poderá, então, ter acesso ao jogo. Para isso, inicialmente, deve selecionar um personagem. Os personagens disponíveis são os mesmos protagonistas do conto. Em seguida, dentro de um cenário que remete ao ambiente da fazenda, palavras irregulares são apresentadas, ocultando-se a letra que gera dúvida ortográfica. Duas letras são apresentadas como opção para completar a palavra: "s" e "z". Ao selecionar a palavra, o sistema indica se a criança acertou ou não. Ao lado da palavra a ser completada é possível encontrar um botão que reproduz um áudio referente a uma frase com a palavra em questão. Optou-se pela voz de uma criança para promover uma melhor interação entre o usuário e o sistema. Os objetivos do áudio são demostrar que o som não auxilia na escolha da letra a ser completada, bem como contextualizar a palavra. Todas as frases emitidas no botão de áudio foram retiradas ou baseadas no conto previamente apresentado.

Para incentivar a criança a permanecer no jogo e completar as palavras, após determinado número de acertos, uma peça de quebra-cabeça surge no cenário, despertando a curiosidade do usuário. A figura 4 apresenta a tela de jogo no qual a palavra a ser completada é "Paisagem". Na figura, à direita da personagem, está surgindo a imagem de uma casa de acordo com os acertos do usuário.

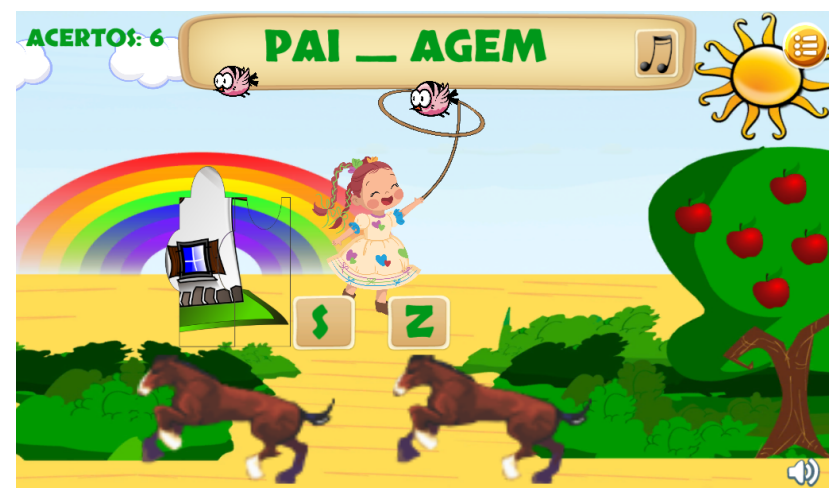

Figura 4. Tela do jogo no qual a criança precisa optar entre duas letras concorrentes para completar a palavra apresentada. 
VI Congresso Brasileiro de Informática na Educação (CBIE 2017)

Anais dos Workshops do VI Congresso Brasileiro de Informática na Educação (WCBIE 2017)

\section{Conclusões}

Este trabalho apresentou um aplicativo para auxiliar o ensino das irregularidades ortográficas. O aplicativo é composto por diferentes ferramentas lúdicas para tornar esse processo mais eficiente e motivante, dentre elas: cenários divertidos, áudios, história ilustrada. Ensinar a Língua Portuguesa de forma lúdica incute nas crianças a ideia de que aprender pode ser uma brincadeira divertida.

Os trabalhos futuros consistem na validação do sistema com alunos do ensino fundamental, analisando o desempenho na aprendizagem das irregularidades ortográficas após a utilização do aplicativo. Além disso, outros módulos do sistema já estão em desenvolvimento para tratar outras dificuldades ortográficas.

Assim, espera-se que diferentes dificuldades da mesma natureza poderão ser abordadas em um mesmo aplicativo. Além disso, espera-se contribuir para uma metodologia diferenciada para o ensino da Língua Portuguesa.

\section{Referências}

Alvarenga, D. (1995). Análise de variações ortográficas. Revista Presença Pedagógica.

Araújo, M. C. C., da Silva, B. R., de Queiroz, J. G., and Viana, W. (2016). Ortomonstro: um audiogame móvel customizável para práticas ortográficas de português por meio do braille. In Anais do XXVII Simpósio Brasileiro de Informática na Educação.

Brasil (1997). Parâmetros curriculares nacionais: Língua portuguesa. Ministério da Educação e do Desporto, Secretaria de Educação Fundamental.

Gaspar, W., Oliveira, E. H. T., and Oliveira, K. M. T. (2015). Aprendizagem da língua portuguesa com dispositivos móveis: Um mapeamento sistemático da literatura. In Anais do XXVI Simpósio Brasileiro de Informática na Educação.

Morais, A. G. (2005). Ortografia na sala de aula, chapter A norma ortográfica do português: o que é, para que serve? como está organizada. Autêntica.

Ouverney-King, J. R., de Oliveira, A. C. C., and das Graças Amorim Castro, M. (2016). Brincar de aprender: ferramentas interdisciplinares no ensino da ortografia. Revista Principia, (30):1-10.

Paschoal, L., Bento, T., Velasco, T., Schocair, C. O., Castaneda, R., Oliveira, T., and Ogasawara, E. (2014). Joe: Jogo ortográfico educacional. In Anais do XXV Simpósio Brasileiro de Informática na Educação.

Unity (2017). www.unity3d.com.

Zorzi, J. L. (2003). Aprendizagem e distúrbios da linguagem escrita: questões clínicas e educacionais. Artmed, Porto Alegre. 